\title{
Multipl Miyelom Tanısı Alan Geriatrik Hastalarda Ağrı ve Yönetimi
}

\section{Pain and Its Management in Geriatric Patients Diagnosed with Multiple} Myeloma

(Derleme)

\author{
Özlem OVAYOLU*, Nimet OVAYOLU**
}

öz

Multipl myelom (MM) plazma hücrelerinin malign bir hastalığı olup, hematolojik kanserler içinde en sık görülen kanser türü olarak karşımıza çıkar ve ileri yaş hastalığı olarak da bilinmektedir. MM tanısı alan hastalar hangi yaş grubunda olursa olsun genellikle ağrı nedeniyle sağlık kurumuna başvurmaktadır. Yapılan çalışmalarda geriatrik bireylerin dışında da MM'li hastaların en sık yaşadığı semptomun ağrı olduğu tespit edilmiştir. Özellikle geriatrik kanser hastalarının yaşadıkları ağrının günlük yaşam aktivitelerini ve kaygı düzeylerini olumsuz etkilediği, ağrı düzeyi arttıkça anksiyetenin de arttığı ve yașam kalitesinin kötüleștiği bildirilmektedir. Tüm bunlar göz önüne alındığında; kanser tanısı alan hastalarda bu semptomun iyi yönetilmesi son derece önemlidir. Ancak son yıllarda kanser tedavisi ve bakımındaki gelişmelere rağmen tüm kanser hastalarında olduğu gibi özellikle geriatrik MM'li hastalarda da etkili ağrı yönetimi sorun olmaya devam etmektedir. $\mathrm{Bu}$ nedenle bu makalede multipl miyelom tanısı alan geriatrik hastalarda ağrı yönetimi incelenecektir.

Anahtar Kelimeler: Ağrı yönetimi, geriatri, multipl miyelom

\section{ABSTRACT}

Multiple myeloma (MM) is a malignant disease of plasma cells and the most common type of cancer a mong hematological cancers, and is also known as advanced age disease. Patients diagnosed with MM usually apply to the health institution due to pain regardless of their age group. The studies have shown that the most common symptom experienced by patients with MM other than geriatric individuals is pain. It is reported that the pain experienced especially by the geriatric cancer patients affect their activities of daily life and anxiety levels negatively

\footnotetext{
*Gaziantep Üniversitesi Sağlık Bilimleri Fakültesi Hemşirelik Bölümü Iç Hastalıkları Hemşireliği Anabilim Dalı, Gaziantep, Türkiye, E-mail: oucan@gantep.edu.tr, Tel: 034236012 00, ORCID: https://orcid.org/0000-0002-7335-4032

**Gaziantep Üniversitesi Sağlık Bilimleri Fakültesi, Gaziantep, Türkiye,

E-mail: ovayolu@gantep.edu.tr, Tel: 0342360 1200, ORCID: https://orcid.org/0000-0002-7335-4032

Geliş Tarihi: 2 Haziran 2017, Kabul Tarihi: 31 Mayıs 2018

***Bu çalışma 7-9 Ekim 2016 tarihlerinde Ankara Üniversitesi Tıp Fakültesinde yapılan 5. Ulusal Geriatrik Hematoloji Kongresinde panel olarak sunulmuştur.

Atıf/Citation: Ovayolu Ö., Ovayolu N. Multiple Miyelom Tanısı Alan Geriatrik Hastalarda Ağrı ve Yönetimi. Hacettepe Üniversitesi Hemşirelik Fakültesi Dergisi 2018; 5(3):..
} 
and the anxiety level increases and the quality of life impairs with increasing pain level. When all of these are taken into account, it is extremely important to manage this symptom well in patients who are diagnosed with cancer. However, despite the improvements in cancer treatment and care in recent years, effective pain management continues to be a problem especially in geriatric patients with MM as in all cancer patients. Therefore, pain management in geriatric patients diagnosed with MM will be examined in this study.

Key Words: Geriatrics, multiple myeloma, pain management.

\section{Giriş̧}

\section{Geriatri ve Multipl Miyelom}

Türkiye'de ve dünyada yaşlı nüfus sayısı hızla artmaktadır¹,2. Ülkemizde Türkiye İstatistik Kurumu nüfus projeksiyonlarına göre yaşlı nüfus oranının 2023 yılında \%10.2, 2075 yılında ise \%27.7’ye yükseleceği tahmin edilmektedir³. Bununla birlikte gerek beklenen yaşam süresinin giderek artması, gerekse son yıllardaki kanser tedavisinde meydana gelen olumlu gelişmeler neticesinde geriatrik onkoloji olgularına da daha sık rastlanmaktadır ${ }^{1,2}$. Yaklaşık olarak tüm kanserlerin \%60'i ve kanserden ölümlerin \%70’i 65 yaş ve üzerinde meydana gelmektedir'. Özellikle ileri yaşlarda gerçekleşen hücresel ve moleküler değişimler kansere yatkınlığa neden olmaktadır. Karsinogenezin geç dönemlerine ait hücrelerin dokularda birikimi, immün ve endokrin sistemdeki değişiklikler, yaşa bağlı telomeraz enziminin dengesizliği, hücrelerin yenilenme ve apoptozis yeteneğini kaybetmesi yaşlılarda kanser gelişimine yol açan mekanizmalar arasında sayılmaktadır ${ }^{5}$. Bu mekanizmaların yol açtığ türlerinden biri de MM'dir. Multipl miyelom, plazma hücrelerinin habis bir hastalığ 1 olup, hematolojik kanserler içinde en sık görülen kanser türü olarak karşımıza çıkar ve ileri yaş hastalığı olarak da ifade edilir. İnsidansı yaşla birlikte artış göstermektedir ve olguların çoğunluğu 60 yaş üzerindedir ${ }^{6,7,8}$. Tüm kanserlerin \%1'ini ve hematolojik malignitelerin \%10'unu oluşturur. Tanı anında ortanca yaş 66 olup, hastaların yalnızca $\% 2$ 'si 40 yaş altında tanı almaktadır ${ }^{10}$. Ayrıca gençlerde tedavi sürecinde yaşlı bireylere göre daha iyi sonuçlar alınmaktadır. Çünkü geriatrik bireylerde organ disfonksiyonları, fizyolojik stresörler, fonksiyonel durumdaki yetersizlik ve eşlik eden hastalıkların artan yükü söz konusudur. Ayrıca hastaneye yatış riskindeki artış, bağımlılık düzeyleri ve yaşam beklentilerinde azalma da bu sonuçta etkilidir. Bütün bunlar özellikle geriatrik MM’li hastalarda "bakım, tedavi ve semptom yönetimini” güçleştirmektedir"11.

\section{Multipl Miyelom ve Ağrı}

Hangi yaş grubunda olursa olsun genellikle MM'li hastaların sağlık kurumuna başvurularında en sık rastlanan semptomlar arasında osteoblastların baskılanması, osteoklastların aktivasyonu ve patolojik kemik kırıkları sonucu ortaya çıkan aygın kemik ağrısı ilk sırada yer almakta ve hastaların yaklaşık \%67'sinde görülmektedir. Yaşanılan bu sorun hastanın hareket yeteneğini kısıtlaması nedeniyle de belirgin olarak sakatlık ve morbiditeye yol açmaktadır ${ }^{6,7,12}$. Özllikle multipl miyelomda ağrının birçok 
sebebi olabilir. Tanı anında rastlanan ağrı, özellikle hastalığın kendisi (yada hastalığa eşlik eden durumlara bağlı iken, hastalığın takibinde gelişen ağrı genellikle uygulanan tedavi) sonrası gelişen nöropatilere bağlıdır $\mathrm{r}^{6,7,8,12}$. Ancak geriatrik bireylerde MM dışında kemik ağrısını taklit edebilecek artrit ve osteoporoz, periferik nöropati benzeri ağrı oluşturabilecek diyabetik nöropati, karpal tünel sendromu veya zona sonrası post herpetik nevralji gibi durumların ağrıya neden olabileceği de unutulmamalıdır ${ }^{12}$. Yapılan çalışmalarda geriatrik bireylerin dışındaki MM'li hastaların da en sık yaşadığg semptomun ağrı olduğu bildirilmektedir ${ }^{8,13,14}$. Geriatrik MM'de ise özellikle kas-iskelet sisteminin farklı alanlarını etkileyen ağrı çok sık yaşanmaktadır. Bu semptomun özellikle yaşlı bireylerde son derece şiddetli olduğ ${ }^{9,11,15}$,fiziksel fonksiyonları ciddi düzeyde etkilediğ $i^{16,20}$ ve oldukça zor kontrol altına alındığı belirtilmektedir ${ }^{20-24}$. Ayrıca geriatri hastalarının yaşadıkları ağrının günlük yaşam aktivitelerini ve kaygı düzeylerini olumsuz etkilediği, ağrı düzeyi arttıkça anksiyetenin de $\operatorname{arttığ~}{ }^{25}$ ve yaşam kalitesinin kötüleştiği bildirilmektedir ${ }^{26}$. Çünkü tedavi edilemeyen ağrı, hastanın fizyolojik fonksiyonlarını, düşünme-iletişim gibi zihinsel fonksiyonlarını, sosyal ilişkilerini olumsuz etkileyerek yaşam kalitesini düşürmekte ve psikolojik bozukluklara neden olmaktadır. Bu nedenle kanser hastaları ölmekten daha çok, ağrı ve ıstırap çekerek ölmekten korkmaktadı1 ${ }^{16,22,23,24}$. Bu doğrultuda hastaların desteklenmesi açısından ağrının düzenli olarak değerlendirilmesi ve optimum semptom yönetimi ile yaşam kalitesinin iyileştirilmesi gerektiği de unutulmamalıdır ${ }^{19,21}$.

\section{Ağrı Yönetimi}

Ağrı subjektif bir bulgu olması nedeniyle ağrı şiddetinin belirlenmesinde primer kaynak hastanın kendisidir ve her hasta ağrısını kendi kelimeleri ile tanımlamalıdır. Eğer olanaklı ise yakınında bulunanların gözlemleri ve çıkardıkları sonuçlardan da yararlanılabilir ${ }^{22}$. Çünkü hem hasta hem de bakım verenlerin ağrı değerlendirmesi etkin ağrı yönetimi açısından önemlidir ${ }^{27}$. Ağrı yönetiminde temel hedef; ağrının en kısa sürede hafifletilmesi ve tekrarının önlenmesidir. Bu amaçla yapılan tedavi yöntemleri genel olarak farmakolojik (girişimsel ve girişimsel olmayan) ve nonfarmakolojik olarak ayrılmaktadır. Farmakolojik olarak Dünya Sağlık Örgütü ağrının şiddetine göre non-opioid, zayıf opioid ve güçlü opioidlerin kullanıldığı üç basamaklı ardışık merdiven tedavisi uygulanmasını önermektedir. Fakat hala, sağlık çalışanları/sağlık sistemi, hasta ve hasta yakınlarına bağlı engeller nedeniyle \%80'lere varan oranlarda ağrının rahatlatılmasında yetersiz kalınmaktadır ${ }^{22,28}$. Sağlık personeline bağlı nedenler arasında; personelin etkin ağrı tedavisi konusunda bilgi eksikliği, semptom kontrolünün tedavi kadar önemsenmemesi, düşük dozla tedavi, tolerans ve bağımlılık korkusu, yasal zorluklar ve ilaçların tam olarak bilinmemesi sayılabilir. Sağlık sistemi kaynaklı nedenler arasında ise; ilaçların ulaşılabilirliğindeki güçlükler, ilaç yönetmeliklerindeki yetersizlikler, araştırma desteğinin az olması ve yasal düzenlemelerdeki eksiklikler yer almaktadır. Hasta kaynaklı nedenler arasında ise; hasta ve yakınlarının narkotik bağımlılığıyla ilgili yanlış inanışları, kanser hastalığında ağrının doğal olduğu düşüncesiyle semptomların gizlenmesi ve tedavi olanaklarının bilinmemesi yer almaktadır ${ }^{22,29}$. Diğer engeller arasında; analjezik tedavisine uyumsuzluk, etkili iletişimin olmaması, ağrıyı tanımlamada ortak bir dilin kullanılmaması, psikolojik, kültürel ve sosyal engeller, ağrının çok yönlü olması, karmaşıklığı, ölçüm yöntemlerinin yetersizliği yer almaktadır ${ }^{22}$. 


\section{Geriatrik Bireylerde Ağrı Yönetimi}

Yaşlı hastada ağrının tedavisini zorlaştıran çeşitli durumlar yaşanabilmektedir. Bunlar arasinda:

- Yaşlı ve bakım verenlerce ağrının yaşlanmanın doğal bir parçası olarak değerlendirilmesi

- Yaşlıların ağrıyı ifade etme problemleri (ağrı yerine başka tanımlamaların kullanılması)

- Kognitif problemleri olan yaşlıların ağrıyı ifade edememesi

- Dini-manevi inanışlar nedeniyle ağrı yakınmasından şikayet edilmemesi (kadercilik gibi)

- Sabırlı ve iyi hasta olma isteği

- Ağrı skalalarının kullanılmasında kognitif, görsel veya duysal problemlere bağlı zorluklar

- Yaşlı bireylerin, yakınlarının ve sağlık çalışanlarının ağrı tedavisinde kullanılan ilaçlar ve ilaç dışı yöntemler konusunda duydukları olası korku ve çekingenlik; tedavi ile ilgili bağımlılık korkusu

- Sağlık çalışanlarının yaşlılarda ağrıyı önemsememesi, sorgulamaması ve yaşlanmanın doğal bir parçası olarak kabul etmeleri

- Sağlık çalışanlarının yaşlı hastalarda ağrı tedavisinin ilkeleri konusunda donanımsız olmaları

- Yaşlılarda ilaç etki, yan etki ve biyoyararlanımını etkileyen çok sayıda komorbiditenin, farmakodinamik ve farmakokinetik değişikliğin varlığı ve böylelikle yaşlılarda ilaç yan etkilerine karşı duyarlılığın artması

- Opioid kullanımını kısıtlayan yasal düzenlemeler

- Yaşlının sağlık kuruluşuna ulaşmasında zorluk

- Ekonomik problemler (maliyet-geri ödeme politikaları gibi) olarak sayılabilir ${ }^{30}$.

Ayrıca ağrı yönetiminde Multipl myelomun geriatrik bireylerde oluşturduğu güçlükler de söz konusudur. Özellikle eşlik eden hastalıkların artması, mevcut terapötiklerin tolere edilebilirliği, çok yaşlı hastaların tedavisi için kanıta dayalı uygulamalardaki sınırlılık, enfeksiyon, tromboembolizm, nöropati ve tedavinin başarısızlığının yüksekliği de ağrı yönetiminde engel olarak karşımıza çıkmaktadır ${ }^{11}$. Bu nedenle geriatrik MM hastalarında destekleyici bakım ve ağrı gibi semptomların kontrolü hayati önem taşımaktadır. Ağrının yönetiminde birinci adım ağrının değerlendirilmesidir. Etkili ağrı yönetimi ağrının dikkatli bir şekilde değerlendirilmesini gerektirir ${ }^{22}$. Özellikle ağrı şiddeti ve süresi düzenli olarak değerlendirilmelidir ${ }^{31}$. Genel ağrının değerlendirilmesinde; ağrının niteliğine, ağrı geçmişine (başlangıç, süre, gidişat gibi), yoğunluğuna, yerleşimine, yayılımına, ağrının artmasına ya da azalmasına neden olabilecek faktörlere, uygulanan ağrı tedavi planına, hastanın tedaviye verdiği yanıta, daha önceki ağrı tedavilerine, önemli psiko-sosyal faktörlere (aile ve diğer destekler, psikiyatrik geçmiş, ağrı tedavisi için risk olabilecek faktörler gibi), ağrıyla ilgili olabilecek diğer özel durumlara (hasta ve ailesi için ağrının anlamı, ağrı ve ağrının ifade edilmesini etkileyebilecek kültürel inanışlar, ruhsal veya dini düşünceler 
gibi) bakılmalıdır²2. Özellikle yaşlı bireylerin ağrı yönetiminde; kapsamlı geriatrik değerlendirme yapılmalı, hastanın ağrısı sistematik olarak değerlendirilmelidir. Tam bir anamnez alınmalı, ağrının ve primer hastalığın bütün ayrıntıları öğrenilmelidir. Ağrının ne zaman başladığı, süresi, sıklığı ve şiddeti değerlendirilmelidir. Bu değerlendirmeler sırasında hastanın ifadesi temel alınmalı, hastaya ve hasta yakınlarına inanılmalıdır. Tedavi planlandıktan sonra ilaç yetersiz ise doz arttırılmalı, yan etki gelişiyorsa ilaç değiştirilmeli, ilaç gereksinimi azalıyorsa doz azaltılmalıdır. Hastaya uygun tedavi yönteminin seçilmesine özen gösterilmelidir ve tedavi planı hastanın gereksinimine göre ve en basit şekilde yapılmalıdır. Ayrıca hasta ve ailesi her aşamada aktif olarak ağrı kontrolüne dahil edilmeli ve ağrının tamamen olmasa da büyük oranda giderilebileceğine ikna edilmelidir ${ }^{11,32}$.

Yaşlı bireylerde, görme, işitme, bilişsel ve motor becerilerdeki değişiklikler ağrı değerlendirme durumlarını etkileyebilir. $\mathrm{Bu}$ nedenle ağrı değerlendirme araçları dikkatle seçilmelidir. Bu araçların seçiminde hastanın eğitim düzeyi ve bilişsel fonksiyonları da göz önünde bulundurulmalıdır ${ }^{33}$. Ayrıca hastanın yaşı, komorbidite yükü, fonksiyonel durumu değerlendirilmeli, opioidlerin yan etkileri dikkatle takip edilmelidir ${ }^{7,8,11}$. İyi bir ağrı yönetiminin temel ilkesi; yeterli düzeyde iletişim kurmaktır. $\mathrm{Bu}$ nedenle sağlık personeli hasta ve ailesi ile güven ilişkisi kurmalı, ağrıyı nasıl değerlendireceğini hastaya öğretmeli, ağrı nedeniyle ortaya çıkabilecek fiziksel ve psikolojik semptomları, fonksiyonel ve bilişsel durumu, konforunun nasıl etkilendiğini değerlendirmeli, hastanın ağrı ile baş etme yöntemlerini sorgulamalı ve hastayı kendi ağrı yönetimiyle ilgili sorumluluk alması için desteklemelidir. Her hastanın ağrıya cevabının ve toleransının; hastanın yaşından, cinsiyetinden, anksiyete ve korku durumundan, iyi hasta olma anlayışından, dini gereksinimlerinden, emosyonel durumundan, kültüründen ve yetiştiği çevreden etkilenebileceği unutulmamalıdır. Ayrıca hastanın tercihleri de dikkate alınmalıdır. Bu nedenle ağrı tedavisinin yanı sıra hastaların tercihleri, korkuları, endişeleri konusunda desteklenmelerinin de ağrının rahatlatılmasına katkı sağlayacağı göz önünde bulundurulmalıdır ${ }^{22,32}$.

Ağrı subjektif bir semptom olduğu için ağrının şiddetini ve/veya karakterini (tipini) belirlememize yarayacak biyolojik bir belirteç veya bir ölçüm metodu yoktur. Ayrıca yaşlı bireyler sıklıkla ağrıyı olduğundan az bildirmeye meyillidir. Öte yandan yaşlıda var olabilen diğer tıbbi problemler ve semptomlar da değerlendirmeyi daha da güçleştirebilir. Bu nedenle bu tür durumlarda bakım verenler yardımcı olabilir. Ayrıca geriatrik bireylerde ağrı ile ilgili inanış ve davranışlar (dini-manevi) ve diğer tıbbi hastalıklar ortaya konulmalı, kognitif fonksiyonlar ve duyusal kayıplar da değerlendirilmelidir. Çünkü duyusal (görsel veya işitsel), ve kognitif bozukluğu olan gruplarda ağrının değerlendirilmesi daha zordur ve bu gruptaki yaşlılar, ağrının yetersiz tedavisi açısından risk altındadır ${ }^{30}$.

Yaşlıda ağrı değerlendirildikten sonra tedavi aşamasına geçilir. Ağrıya yönelik bir tedavi planı oluştururken, yaşlı bireyin almakta olduğu ilaçların, komorbid ve psikososyal problemlerin bilinmesi gerekir. Ayrıca yaşlılarda analjezik seçeneklerinin sınırlı olabileceği, yaşlılar tarafından sıklıkla kullanılan analjeziklerin veya adjuvan ilaçların farmakokinetiği ve farmakodinamiğinde yaşlanma ile oluşan değişiklikler, olası yan etkileri, göreceli ve kesin kontrendikasyonları, önemli ilaç-ilaç etkileşimlerinin de bilinmesi gerekir. Yaşlıda farmakolojik tedavinin temel ilkesi analjeziklere düşük 
dozlarda başlayıp yavaş yavaş istenilen doza gelmektir. Ağrının tipi ve şiddeti, böbrek ve karaciğer fonksiyonları, mevcut olan polifarmasi, eşlik eden semptomlar, ilaçların elde edilebilirliği ve maliyeti de analjezik seçimini etkiler ${ }^{30}$. Ancak her yaş grubunda en başarılı ağrı yönetimi farmakolojik ve farmakolojik olmayan terapilerin kombinasyonu ile elde edilir. Bu nedenle etkin ağrı yönetiminde kanıt temelli farmakolojik ve nonfarmakolojik yöntemler kullanılmalıdır. Farmakolojik olarak en geniş kabul görmüş algoritma Dünya Sağlık Örgütü tarafından geliştirilmiş olan analjezik basamak tedavisi yöntemidir. Ayrıca ağrı tedavisinde sinir blokajları, analjeziklerin bölgesel infüzyonu (epidural, intratekal ve bölgesel pleksuslar), nörostimülasyon uygulamaları (özellikle kemoterapinin neden olduğu ağrılı periferal nöropatilerde), radyofrekans ablasyon (yeterli analjeziye ulaşılamayan kemik lezyonlarının ağrı tedavisinde) ve açık cerrahi girişimler gibi girişimsel yöntemler de kullanılmaktadır., ${ }^{7,13}$ Yaşlı hastanın ağrı yönetiminde nonfarmakolojik yöntem olarak da; sıklıkla hasta eğitimi, günlük yaşam aktivitelerinde değişiklikler, egzersizler, fizik tedavi ve rehabilitasyon tedavi yöntemleri ve psikoterapi kullanılmaktadır ${ }^{34}$.

\section{SONUÇ}

Yaşlı bireylerde MM ile ilişkili semptom ve komplikasyonların tedavisi ve yönetimi oldukça zordur. Ancak bu hastaların semptomlarının dikkatli ve periyodik olarak değerlendirilmesi, destekleyici tedavi yaklaşımlarının akılcı kullanımı sayesinde şefkatli ve etkili bir bakım sağlanabilir. Böylece ağrı gibi yaşam kalitesini olumsuz etkileyen semptomlar da daha rahat kontrol altına alınabilirr ${ }^{11}$. Ağrı, hastalık evresinden bağımsız olarak yaşanan bir semptomdur. Ancak bu semptom çoğunlukla yeteri kadar önemsenmez ve çoğu zaman yeterli tedavisi yapılamaz. Bu nedenle ağrı yönetiminin öncelikli hedefler arasına alınması gerekir. Ayrıca kanser ağrısının yeterli düzeyde tedavisini sağlayabilmek için, analjezik ajanların farmakokinetiğini ve farmakodinamiğini etkileyen faktörlerin, tedaviyi engelleyen nedenlerin tam olarak kavranması gerekir. Başarılı bir kanser ağrı tedavisi programında multidisipliner yaklaşım $^{30}$ ve özellikle multipl myelom tanısı alan hastaların ağrı yönetiminde ekip yaklaşımının kilit rolde olduğ ${ }^{35}$ unutulmamalı, ağrı yönetiminde analjeziklerin kombinasyonunun yanında duygusal, psikolojik ve ruhsal destek de tedavide yer almalıdır ${ }^{30}$.

Sonuç olarak, yaşlanmayla ilişkili tüm dezavantajlara rağmen, uygun yaklaşımlar ve kabul edilebilir bir yan etki profili ile çoğu yaşlıda yeterli ağrı kontrolü sağlanabilir. Ancak yaşlıların özel ihtiyaçlarına odaklı profesyonel eğitim programlarına, klinik pratiğe rehberlik edecek araştırmalara ve daha iyi ağrı tedavi stratejilerine de ihtiyaç $\operatorname{vard} 1 r^{30}$

\section{KAYNAKLAR}

1. BuskeC,Hiddemann W. Theolder patient with malignant diseases. Internist(Berl). 2007;48(11):1206,120810.

2. Emin Erdem M, Akın S, Tanrıkulu S, Kazan S, Yalçın C, Özdemir P, Erdoğan M, Kılıç Aydın D, Tekçe M, Aliustaoğlu M. Kliniğimize Yatırılan Geriatrik Onkoloji Olgularının Geriye Dönük Değerlendirilmesi. J Kartal TR 2016;27(1):42-6. 
3. Sağlık Bakanlığı Sağlık İstatistikleri Yıllığı 2012;31. http://www.saglik.gov.tr/Eklenti/2772,sihbpdfpdf. pdf?0. Erişim Tarihi:12.05.2017.

4. Alan Ö, Gürsel Ö, Ünsal M, Altın S, Kılçıksız S. Geriatrik Hastalarda Onkolojik Yaklaşım. Okmeydanı Tip Dergisi 2013;29(Ek say1 2):94-98.

5. Bostankolu Ö, Öztürk B, Coşkun U, Süleyman Büyükberber S, Benekli M. Yaşlı Hastalarda Kanser Kemoterapisi. Uluslararası Hematoloji-Onkoloji Dergisi UHOD 2008;3:18.

6. Ramsenthaler C, Osborne TR, Gao W, Siegert RJ, Edmonds PM, Schey SA, Higginson IJ. The impact of disease-related symptoms and palliative care concerns on health-related quality of life in multiple myeloma: a multi-centre study. BMC Cancer. 2016;7(16):427.

7. Molloy S, Lai M, Pratt G, Ramasamy K,Wilson D, Quraishi N, Auger M, Cumming D, Punekar M, Quinn M, Ademonkun D,Willis F, Tighe J, Cook G, Stirling A, Bishop T,Williams C, Boszczyk B, Reynolds J,Grainger M, Craig N,Hamilton A,Chalmers I, Ahmedzai S, Selvadurai S, Low E, Kyriakou C. Optimizing the management of patients with spinal myeloma disease. British Journal of Haematology 2015;171:332-343.

8. Sloot S, Boland J, Snowden JA, Ezaydi Y, Foster A, Gethin A, Green T, Chopra L, Verhagen S, Vissers K, Engels Y, Ahmedzai SH. Side effects of analgesia may significantly reduce quality of life in symptomatic multiple myeloma: a cross-sectional prevalence study. Support Care Cancer 2015;23:671-678.

9. Southerst D, Dufton J, Stern P. Multiple Myeloma presenting as sacroiliac joint pain: a case report. J Can Chiropr Assoc. 2012;56(2).

10. Multipl Myelom Tanı ve Tedavi Kılavuzu. http://www.thd.org.tr/thdData/Books/77/ kilavuzu. Erişim Tarihi 12.05.2017.

11. Willan J, Eyre TA, Sharpley F, Watson C, King AJ, Ramasamy K. Multiple myeloma in the very elderly patient: challenges and solutions. Clinical Interventions in Aging 2016:11.

12. Kırkızlar HO, Akpınar S, Acar Ş, Demir M. Multipl miyelom ve ağrı yönetimi. Türkiye Klinikleri J Hem Onc-Special Topics 2011;4(2):73-80.

13. Niscola P, Siniscalchi A, Tendas A, de Fabritiis P, Caravita T, Efficace F. Towards a better understanding of the relationship between side effects of analgesia and quality of life in patients with multiple myeloma. Support Care Cancer. 2016;24(1):9-10.

14. Hameed A, Brady JJ, Paul Dowling P, Clynes M, O'Gorman P. Bone disease in multiple myeloma: pathophysiology and management. Cancer Growth and Metastasis 2014;10; 7: 33-42.

15. Eslick R, Talaulikar D. Multiple myeloma: from diagnosis to treatment. Aust Fam Physician 2013;42(10):684-8.

16. Van Lancker A, Velghe A, Van Hecke A, Verbrugghe M, Den Noortgate NV, Grypdonck M, Verhaeghe S, Bekkering G, Beeckman D. Prevalence of Symptoms in Older Cancer Patients Receiving Palliative Care: A Systematic Review and Meta-Analysis. Journal of Pain and Symptom Management 2014;47(1):90-104.

17. Yong K, Delforge M, Driessen C, Fink L, Flinois A, Gonzalez-McQuire S, Safaei R, Karlin L, Mateos MV, Raab MS, Schoen P, Cavo M. Multiple myeloma: patient outcomes in real-world practice, Br J Haematol. 2016;175(2):252-264.

18. Boland E, Eiser C, Ezaydi Y, Greenfield DM, Ahmedzai SH, Snowden JA. Living with advanced but stable multiple myeloma: a study of the symptom burden and cumulative effects of disease and intensive (hematopoietic stem cell transplant-based) treatment on health-related quality of life. J Pain Symptom Manage. 2013;46(5):671-80.

19. Ramsenthaler C, Kane P, Gao W, Siegert RJ, Edmonds PM, Schey SA, Higginson IJ. Prevalence of symptoms in patients with multiple myeloma: a systematic review and meta-analysis. Eur J Haematol. 2016;97(5):416-429.

20. Heinrich M, Fisher A, Paton B, McCourt O, Beeken RJ, Hackshaw A, Wardle J, Yong K. Lifestyle in multiple myeloma-a longitudinal cohort study protocol. BMC Cancer. 2016;4;16:387. 
21. Molassiotis A, Wilson B, Blair S, Howe T, Cavet J. Unmet supportive care needs, psychological well-being and quality of life in patients living with multiple myeloma and their partners. Psychooncology. 2011;20(1):88-97.

22. Arslan D, Tatlı AM, Üyetürk Ü. Kansere bağlı ağrı ve tedavisi. Abant Med J 2013;2(3):256-260.

23. Paice JA, Ferrell B. The management of cancer pain. CA Cancer J Clin. 2011;61(3):157-82.

24. Stockler MR, Wilcken NR. Why is management of cancer pain still a problem? J Clin Oncol. 2012;1;30(16):1907-8.

25. Mutluay E, Yurtsever S. Geriatrik kanser hastalarında kronik ağrı ve kaygı. Türk Geriatri Dergisi 2014;17(2):164-171

26. Ovayolu Ö, Ovayolu N. Semptom yönetiminde kanıt temelli tamamlayıcı yöntemler. Erciyes Üniversitesi Sağlık Bilimleri Fakültesi Dergisi 2013;1(1):83-98.

27. Ovayolu Ö, Ovayolu N, Aytaç S, Serçe S, Sevinc A. Erratum to: Pain in cancer patients: pain assessment by patients and family caregivers and problems experienced by caregivers. Support Care Cancer. 2015;23(7):1865.

28. Sarıhan E, Kadığlu E, Artıran İğde F. Kanser ağrısı, tedavi prensipleri ve Dünya Sağlık Örgütü ağrı basamak tedavisi. Nobel Med 2012; 8(1): 5-15.

29. Uzunoğlu S, Çiçin İ. Kanser hastalarında ağrıya yaklaşım. Klinik Gelişim 2011;24:14-20.

30. Bahat Öztürk G, Karan MA. Yaşlıda ağrıya yaklaşım. http://www.akadgeriatri.org/managete/fu_ folder/2009-01/html/2009-1-1-031-044.htm, Erişim Tarihi: 13.05.2017.

31. Porta-Sales J, Nabal-Vicuna M, Vallano A, Espinosa J, Planas-Domingo J, Verger-Fransoy E, JuliàTorras J, Serna J, Pascual-López A, Rodríguez D, Grimau I, Morlans G, Sala-Rovira C, Calsina-Berna A, Borras-Andrés JM, Gomez-Batiste X. Have we improved pain control in cancer patients? a multicenter study of ambulatory and hospitalized cancer patients. J Palliat Med. 2015;18(11):923-32.

32. Uğur Ö. Kanser hastasının semptom yönetimi. Türk Onkoloji Dergisi 2014;29(3):125-135.

33. Chang HC, Lai YH, Lin KC, Lee TY, Lin HR. Evaluation of pain intensity assessment tools among elderly patients with cancer in Taiwan. Cancer Nurs. 2016 Jun 21.

34. Ağrı, Birinci Basamak Sağlık Hizmetlerinde Çalışan Hekimler İçin Yaşlı Sağlığı Tanı ve Tedavi Rehberi 2010, T.C. Sağlık Bakanlığı Temel Sağlık Hizmetleri Genel Müdürlüğü. https://sbu.saglik.gov.tr/ Ekutuphane/kitaplar/t3.pdf. Erişim Tarihi: 27.04.2018.

35. Poulos AR, Gertz MA, Pankratz VS, Post-White J. Pain, mood disturbance, and quality of life in patients with multiple myeloma. Oncol Nurs Forum. 2001;28(7):1163-71. 